\title{
Evaluation of Ethiopian Wheat Germplasm Against Yellow Rust (Puccinia striiformis) Disease Under Field Condition
}

\author{
Daniel Kasa, Tamirat Negash \\ Ethiopian Institute of Agricultural Research (EIAR), Kulumsa Agricultural Research Center, Asela, Ethiopia \\ Email address: \\ danikasa2008@gmail.com (D. Kasa)

\section{To cite this article:} \\ Daniel Kasa, Tamirat Negash. Evaluation of Ethiopian Wheat Germplasm Against Yellow Rust (Puccinia striiformis) Disease Under Field \\ Condition. Agriculture, Forestry and Fisheries. Vol. 10, No. 2, 2021, pp. 61-65. doi: 10.11648/j.aff.20211002.14
}

Received: December 23, 2020; Accepted: January 29, 2021; Published: March 10, 2021

\begin{abstract}
Wheat rust outbreak especially yellow rust is the major production constraint in Ethiopia. Arsi Zone is the hot spot zone for yellow rust (Puccinia striiformis (Pst)) particularly Meraro and Bekoji sites are frequently yellow rust epidemic was occur due favorable environmental and higher pressure of inoculums in the areas. Therefore, the objective the study was to identify sources of resistance against yellow rust at adult plant stage under hot spot sites. In this study, Three hundred seventy five elite breeding and advanced lines were planted at Meraro, Arsi-Robe and Bekoji. The results show that 34, 10 and 54\% of the lines at Meraro were found resistant to moderately resistant, intermediate and moderately susceptible to susceptible. At Arsi-Robe 61, 23.5 and $15.5 \%$ of lines were showed that resistant to moderately resistant, intermediate and moderately susceptible to susceptible. Finally, at Bekoji 35.5, 21.3 and 43.2\% lines at were resistant to moderately resistant, intermediate and moderately susceptible to susceptible category of yellow rust. Average coefficient of infection (ACI) less than $20 \%$ showed at Meraro (34\%), Bekoji (35.5\%) and Arsi-Robe (61\%) was good percent of resistance to the current yellow rust pressure respectively, indicating higher disease pressure at Meraro and Bekoji than that of Arsi-Robe. Among the lines, 43.7\% showed a good level of resistance ( $<30 \%$ severity) in all locations. Generally, most of the lines, which showed better resistance at Arsi-Robe, were susceptible at Meraro and Bekoji.
\end{abstract}

Keywords: Wheat, Puccinia striiformis, Yellow Rust, Hot Spots

\section{Introduction}

In Ethiopia wheat (Triticum aestivum) is one of the staple food crops cultivated by 5 million small scale farmers and it is covered 1.7 million hectares and it accounts for $13.49 \%$ of the cropland, with an annual production of 4.5 million metric tons in the country [6]. Wheat contributes about $15.63 \%$ of the grain production in the country. In terms of area, wheat ranks fourth after teff, maize and sorghum and the mean wheat yield in Ethiopia is estimated to be $2.67 \mathrm{t} \mathrm{ha}^{-1}$ [6], which is well below the world mean of $3.0 \mathrm{t} \mathrm{ha}^{-1}$ [9]. This is due to losses caused by biotic and a biotic constraints $[1,10]$. Among biotic constraints wheat rusts are the main restrictive factors for wheat production in Ethiopia [1]. From rusts especially, yellow rust can cause yield losses of up to $100 \%$ on susceptible cultivars if infection was occurs at early stage and the disease continues to develop during all growing season $[3,11]$. The impact of yellow rust varies depending upon the susceptibility of cultivar, earliness of the initial infection, rate of disease development and duration of the disease [5]. Yellow rust epidemics are becoming more frequent in Ethiopia. According to Mozgovoy [12], epidemics of yellow rust occurred in 1977, 1980-83 and 1986, resulting 30-40\% yield losses In another report, grain yield losses up to $96 \%$ were impose on susceptible wheat cultivars [18]. The Epidemics occurred from in 1998-1990 have resulted in $58 \%$ of yield loss [4]. Therefore, the past two decades, frequent epidemics of yellow rust have been a major challenge to wheat production in the country. Releasing of genetically resistant cultivars and chemical option are the two major management of yellow rusts disease in Ethiopia as well as in worldwide. According to Chen [5] research report increasing resistant cultivars is preferred approach for control of yellow rust because it is an effective, easy-to-use, economic and environmentally friendly strategy. on the other hand, resistant cultivars become susceptible due to dynamics of pathogen within the population. Therefore, searching for resistance sources to the current yellow rusts 
diseases is becoming crucial. The objective of this study was to identify yellow rust resistance genotype/elite lines at adult plant stage (APR) under hot spot sites.

\section{Materials and Methods}

A total of 375 elite bread wheat lines that were either selected from international nurseries including resistant and susceptible check were used for study. From resistant cultivars (Danda'a, Wane, and Kingbird Daka) and susceptible check varieties (Kekeba and Lemu) were repeatedly planted at certain intervals of test lines. Natural yellow rust epidemics were enhanced by planting a mixture of spreader rows of PBW343, Kubsa, Digalu and Morocco in perpendicular to the test entries in 2019 main cropping season. Plots were kept weed free by two times hand weeding. When the susceptible check started to show yellow rust development, scoring of severity was carried out using the modified Cobb scale [13]. Average Coefficients of Infection $(\mathrm{ACI})$ were calculated by taking into account the severity of yellow rust of the lines and cultivars, and their field response [14] in addition, genotypes were compared for resistance using final rusts severity score, field reaction and average coefficient of infection. The scores were converted into average coefficients of infection, by multiplying severity by an assigned value for the field response, as suggested by Stubbs et al. [14] (Table 1). The constant value was further modified to include infection responses of resistant to moderately resistant $(\mathrm{RMR}=0.3)$ and moderately susceptible to susceptible (MSS=0.9).

Table 1. Field response values according to Stubbset al. [14] with some modifications.

\begin{tabular}{lll}
\hline Field response & Symbol & Constant value \\
\hline Zero (Very resistant) & 0 & 0 \\
Resistant & $\mathrm{R}$ & 0.2 \\
Resistant to moderately resistant & $\mathrm{RM}$ & 0.3 \\
Moderately resistant & $\mathrm{MR}$ & 0.4 \\
Intermediate & $\mathrm{M}$ & 0.6 \\
Moderately susceptible & $\mathrm{MS}$ & 0.8 \\
Moderately susceptible to susceptible & $\mathrm{MSS}$ & 0.9 \\
Susceptible & $\mathrm{S}$ & 1.0 \\
\hline
\end{tabular}

$\mathrm{R}=$ resistant, $\mathrm{RMR}=$ resistant to moderately resistant, $\mathrm{MR}=$ moderately resistant, $\mathrm{M}=$ moderately resistant to moderately susceptible, $\mathrm{MS}=$ moderately susceptible, MSS = moderately susceptible to susceptible and S = susceptible

\section{Results}

\subsection{Reactions of the Evaluated Genotype}

From 375 elite breeding and advanced lines at Meraro, Arsi Robe and Bekoji 15, 1 and 31 were immune against all the races of yellow rust prevailing in nature respectively (Table 2). However, at all locations none of the test lines show Resistant (R) and Resistant to moderately resistant (RM). One hundred ten, four and one hundred eleven lines were exhibiting moderately resistant (MR) at the three locations (Tabel 2). Whereas 17, 6 and 4 genotype show intermediate $(\mathrm{M})$ reactions at Meraro, Arsi Robe and Bekoji respectively, twenty lines and forty-two at Meraro and Arsi Robe showed moderately susceptible (MS) reactions and 60 lines at Bekoji. With respect to moderately susceptible to susceptible reactions (MSS) 9, 16 and 8, displayed this reaction at Meraro, Arsi Robe and Bekoji. Majority of the elite lines and cultivars was show completely susceptible (S) reaction at Meraro, Arsi Robe and Bekoji with 204,306 and 160 respectively. In general, considering the disease reactions at Meraro and Arsi Robe, more lines were in the susceptible categories at Meraro and Arsi Robe than at Bekoji (Figure 1). However, in reaction categories which is show moderately resistant, the number of lines at Meraro and Bekoji exceeded by far the number of lines at Arsi Robe (Figure 1)

Table 2. Number of bread wheat genotype/lines included check in resistance and susceptibility categories for yellow rust.

\begin{tabular}{|c|c|c|c|c|}
\hline \multirow{2}{*}{ No } & \multirow{2}{*}{$\begin{array}{l}\text { Reaction } \\
\text { category }\end{array}$} & \multicolumn{3}{|c|}{ Number of genotype/lines } \\
\hline & & Meraro & Arsi Robe & Bekoji \\
\hline 1 & 0 & 15 & 1 & 31 \\
\hline 2 & $\mathrm{R}$ & 0 & 0 & 0 \\
\hline 3 & $\mathrm{RM}$ & 0 & 0 & 0 \\
\hline 4 & MR & 110 & 4 & 111 \\
\hline 5 & M & 17 & 6 & 4 \\
\hline 6 & MS & 20 & 42 & 60 \\
\hline 7 & MSS & 9 & 16 & 8 \\
\hline 8 & $\mathrm{~S}$ & 204 & 306 & 160 \\
\hline
\end{tabular}

$\mathrm{R}=$ resistant, $\mathrm{RMR}=$ resistant to moderately resistant, $\mathrm{MR}=$ moderately resistant, $\mathrm{M}=$ moderately resistant to moderately susceptible, $\mathrm{MS}=$ moderately susceptible $\mathrm{MSS}=$ moderately susceptible to susceptible and $\mathrm{S}=$ susceptible

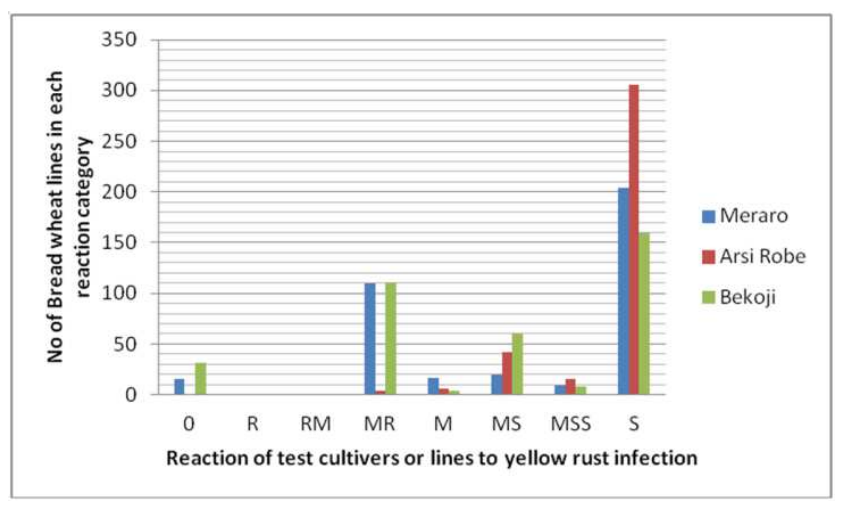

Figure 1. Number of bread wheat genotyp/elite lines in different classes of yellow rust reactions at Meraro, Arsi Robe and Bekoji in 2019.

\subsection{Severity of Yellow Rust}

Majority of the taste lines (131 and 133) tested at Meraro, and Bekoji (Figure 2) showed a severity $\leq 20 \%$; whereas at Arsi Robe, almost two-third of the line (229) showed the same severity levels (Figure 2). 41, 88 and 80 display a severity range between $21-30 \%$ at Meraro, Arsi robe and Bekoji respectively. 203, 58 and 162 genotype/lines show severity range $>30 \%$. 


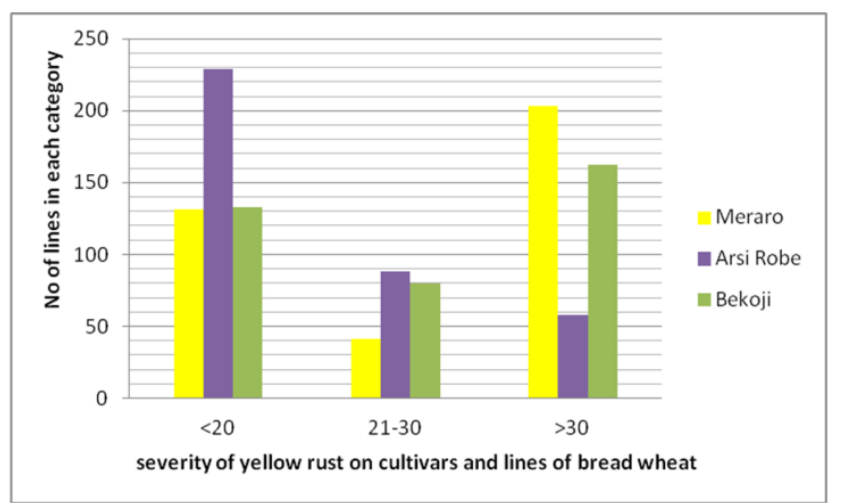

Figure 2. Bread wheat genotype/Elite lines evaluated in Meraro, Arsi Robe and Bekoji and their severity levels.

Terminal yellow rust severity less than or equal to ten percent and coefficient of infection

The selection of elite bread wheat lines was made based on the occurs of the highest yellow rust pressers site from the three yellow rust hot spot areas. In 2019 main cropping season the highs yellow rust pressers was occurrence at Meraro than the other hot spot location. Therefore, we are select the terminal severity of the yellow rust leas than or equal to ten percent by correcting of the other hot pot location. The selection was made by considering the three parameters, the highest score was recorded for elite line KU18BWOL 3399 (Table 3). The least score was recorded for elite bread wheat line KU18BWPL1_29 (Table 3). Two elite lines show an average coefficient of infection (ACI) value of less than or equal two. These included lines KU18BWOE_134 and KU18BWOE_69. Generally 39 (79\%) of the test genotypes displayed an ACI value of less than or equals to ten percent of the coefficient of infection. On the other hand $10(20 \%)$ The test genotype show as greater than or equals to ten.

\subsection{Response of the Check Cultivars Against Yellow Rust in Hot Spot Areas}

When see the average disease severity in check cultivars and it is response almost all check cultivars was moderately susceptible to susceptible reactions except wane at Meraro, Arsi-Robe and Bekoji. The responses of check cultivars against yellow rust was score $24,34,46.8$ and $46.5 \%$ on Wane, Lemu, King-bird and Kekeba in all location respectively (Figure 3). From the chekek cultivars the highest disease severity was recorded on King-bird and Kekeba.

Table 3. Terminal yellow rust severity, coefficient of infection and average coefficient of infection of selected elite wheat lines in Meraro, Bekoji and Arsi-Robe testing sit.

\begin{tabular}{|c|c|c|c|c|c|c|c|c|c|}
\hline \multirow{2}{*}{ Plot } & \multirow{2}{*}{ Genotype } & \multirow{2}{*}{ Seed source } & \multicolumn{3}{|c|}{ Terminal yellow rust severity } & \multicolumn{3}{|l|}{ CI-value } & \multirow{2}{*}{$\begin{array}{l}\text { ACI } \\
\text { value }\end{array}$} \\
\hline & & & Meraro & A/Robe & Bekoji & Meraro & A/Robe & Bekoji & \\
\hline 16 & BW120101 & KU18BWOE_14 & $10 \mathrm{mr}$ & $5 \mathrm{~ms} / \mathrm{mr}$ & $5 \mathrm{mr}$ & 4 & 3 & 2 & 3 \\
\hline 24 & BW120109 & KU18BWOE_228 & $10 \mathrm{mr}$ & $30 \mathrm{~s}$ & $5 \mathrm{mr}$ & 4 & 30 & 2 & 12 \\
\hline 28 & BW120115 & KU18BWOE_323 & 0 & $10 \mathrm{~s}$ & 0 & 0 & 9 & 0 & 3 \\
\hline 29 & BW120116 & KU18BWOE_134 & $10 \mathrm{mr}$ & $\mathrm{Tmr}$ & 0 & 4 & 0.4 & 0 & 1.5 \\
\hline 30 & BW120118 & KU18BWOE_69 & $10 \mathrm{mr}$ & $5 \mathrm{mr}$ & 0 & 4 & 2 & 0 & 2 \\
\hline 47 & BW120137 & KU18BWOE_52 & 0 & $5 \mathrm{~s}$ & $5 \mathrm{mr}$ & 0 & 5 & 2 & 2.3 \\
\hline 104 & BW172800 & KU18BWOE_53 & $10 \mathrm{mr}$ & $10 \mathrm{~ms} / \mathrm{mr}$ & $\mathrm{tmr}$ & 4 & 6 & 0.4 & 3.5 \\
\hline 111 & BW172831 & KU18BWOE_332 & $10 \mathrm{mr}$ & $5 \mathrm{~ms}$ & $15 \mathrm{~ms}$ & 4 & 4 & 12 & 6.7 \\
\hline 112 & BW174116 & BW18NE2_12 & 0 & $10 \mathrm{~s}$ & 0 & 0 & 10 & 0 & 3.3 \\
\hline 113 & BW174298 & KU18BWOE_237 & 0 & $20 \mathrm{~s}$ & $\mathrm{tmr}$ & 0 & 20 & 0.4 & 6.8 \\
\hline 115 & BW174334 & KU18BWOE_93 & $10 \mathrm{mr}$ & $10 \mathrm{~s}$ & 0 & 4 & 10 & 0 & 4.7 \\
\hline 118 & BW174371 & KU18BWOE_125 & 0 & $30 \mathrm{~s}$ & 0 & 0 & 30 & 0 & 10 \\
\hline 120 & BW174388 & KU18BWOE_248 & 0 & $15 \mathrm{~s}$ & 0 & 0 & 15 & 0 & 5 \\
\hline 124 & BW174413 & KU18BWOE_330 & $10 \mathrm{mr}$ & $5 \mathrm{~ms}$ & $\operatorname{tmr}$ & 4 & 4 & 0.4 & 2.8 \\
\hline 125 & BW174414 & KU18BWOE_301 & $10 \mathrm{~ms} / \mathrm{s}$ & $20 \mathrm{~s}$ & 0 & 9 & 20 & 0 & 9.7 \\
\hline 127 & BW174425 & KU18BWOE_31 & $10 \mathrm{mr}$ & $30 \mathrm{~s}$ & $5 \mathrm{mr}$ & 4 & 30 & 2 & 12 \\
\hline 128 & BW174427 & KU18BWOE_147 & 0 & $10 \mathrm{~s}$ & 0 & 0 & 10 & 0 & 3.3 \\
\hline 129 & ETBW9080 & BW18NE1_11 & 0 & $20 \mathrm{~s}$ & 0 & 0 & 20 & 0 & 6.7 \\
\hline 134 & ETBW9452 & BW18NE1_14 & $10 \mathrm{msmr}$ & $10 \mathrm{~s}$ & 0 & 6 & 10 & 0 & 5.3 \\
\hline 153 & BW120052 & KU18BWOL_114_248 & $10 \mathrm{~s}$ & $20 \mathrm{~s}$ & $\operatorname{tmr}$ & 10 & 20 & 2 & 10.7 \\
\hline 165 & BW120069 & KU18BWOL_66_265 & $10 \mathrm{mr}$ & $15 \mathrm{~ms}$ & $20 \mathrm{~ms}$ & 4 & 12 & 16 & 10.7 \\
\hline 172 & BW172093 & AA18BWNE2_24 & $10 \mathrm{mr}$ & $10 \mathrm{~ms}$ & $10 \mathrm{sms}$ & 4 & 8 & 9 & 7 \\
\hline 176 & BW172144 & AA18BWNE2_17 & $10 \mathrm{mr}$ & $20 \mathrm{~s}$ & $\mathrm{tmr}$ & 4 & 20 & 2 & 8.7 \\
\hline 186 & BW172440 & KU18BWOL_339_91 & $10 \mathrm{~ms}$ & $30 \mathrm{~s}$ & $10 \mathrm{mr}$ & 8 & 30 & 4 & 14 \\
\hline 194 & BW172550 & KU18BWOL_199_115 & $10 \mathrm{mr}$ & $20 \mathrm{~s}$ & $\mathrm{tmr}$ & 4 & 20 & 0.4 & 8.1 \\
\hline
\end{tabular}


Table 3. Continued.

\begin{tabular}{|c|c|c|c|c|c|c|c|c|c|}
\hline \multirow{2}{*}{ Plot } & \multirow{2}{*}{ Genotype } & \multirow{2}{*}{ Seed source } & \multicolumn{3}{|c|}{ Terminal yellow rust severity } & \multicolumn{3}{|l|}{ CI-value } & \multirow{2}{*}{$\begin{array}{l}\text { ACI } \\
\text { value }\end{array}$} \\
\hline & & & Meraro & A/Robe & Bekoji & Meraro & A/Robe & Bekoji & \\
\hline 195 & BW172558 & KU18BWOL_61_118 & $10 \mathrm{mr}$ & $20 \mathrm{~s}$ & $\mathrm{tmr}$ & 4 & 20 & 0.4 & 8.1 \\
\hline 234 & BW174187 & KU18BWOL_137_171 & $10 \mathrm{mr}$ & $15 \mathrm{~ms}$ & $\operatorname{tmr}$ & 4 & 12 & 0.4 & 5.5 \\
\hline 236 & BW174456 & AA18BWNE2_8 & $10 \mathrm{msmr}$ & $20 \mathrm{~s}$ & $5 \mathrm{mr}$ & 6 & 20 & 2 & 9.3 \\
\hline 263 & ETBW 9080 & AA18BWNE1_11 & 0 & 0 & $\operatorname{tmr}$ & 0 & 0 & 0.4 & 0.1 \\
\hline 271 & ETBW 9396 & AA18BWNE1_13 & 0 & $30 \mathrm{~s}$ & $10 \mathrm{mr}$ & 0 & 30 & 4 & 11.3 \\
\hline 290 & ETBW 9661 & AA18BWNE2_7 & $10 \mathrm{mr}$ & $20 \mathrm{~s}$ & $\mathrm{tmr}$ & 4 & 20 & 0.4 & 8.1 \\
\hline 292 & ETBW9547 & KU17BWNL_15 & $10 \mathrm{mr}$ & $30 \mathrm{~s}$ & $\operatorname{tmr}$ & 4 & 30 & 0.4 & 11.5 \\
\hline 296 & BW173457 & KU18BWPE3_26 & $10 \mathrm{mr}$ & $15 \mathrm{~s}$ & $10 \mathrm{mr}$ & 4 & 15 & 4 & 7.7 \\
\hline 298 & BW173528 & KU18BWPE2_29 & $10 \mathrm{mr}$ & $25 \mathrm{~s}$ & $10 \mathrm{mr}$ & 4 & 25 & 4 & 11 \\
\hline 302 & ETW17-271 & KU18BWPE1_2 & $10 \mathrm{msmr}$ & $20 \mathrm{~s}$ & $\mathrm{tmr}$ & 6 & 20 & 0.4 & 8.8 \\
\hline 323 & ETW17-476 & KU18BWPE3_12 & 0 & $15 \mathrm{~s}$ & 0 & 0 & 15 & 0 & 5 \\
\hline 329 & BW164003 & EYT_22 & 0 & $15 \mathrm{~s}$ & 0 & 0 & 15 & 0 & 5 \\
\hline 330 & BW164004 & EYT_65 & $10 \mathrm{mr}$ & $30 \mathrm{~s}$ & 0 & 4 & 30 & 0 & 11.3 \\
\hline 333 & BW164007 & EYT_81 & $10 \mathrm{mr} / \mathrm{ms}$ & $10 \mathrm{~ms} / \mathrm{s}$ & $10 \mathrm{mr}$ & 6 & 9 & 4 & 6.3 \\
\hline 334 & BW164008 & EYT_99 & $10 \mathrm{mr}$ & $15 \mathrm{~ms} / \mathrm{s}$ & $20 \mathrm{~ms}$ & 4 & 13.5 & 16 & 11.2 \\
\hline 343 & BW172020 & KU18BWPL4_11 & $10 \mathrm{mr}$ & $15 \mathrm{~s}$ & 0 & 4 & 15 & 0 & 6.3 \\
\hline 353 & BW174019 & KU18BWPL3_19 & $10 \mathrm{mr}$ & $30 \mathrm{~s}$ & $10 \mathrm{mr}$ & 4 & 30 & 4 & 12.7 \\
\hline 356 & ETW17-133 & KU18BWPL2_7 & $10 \mathrm{mr}$ & $15 \mathrm{~s}$ & $\operatorname{tmr}$ & 4 & 15 & 0.4 & 6.5 \\
\hline 358 & ETW17-143 & KU18BWPL2_24 & $10 \mathrm{mr} / \mathrm{ms}$ & $10 \mathrm{~s}$ & $30 \mathrm{~s}$ & 6 & 2 & 30 & 12.7 \\
\hline 362 & ETW17-193 & KU18BWPL3_8 & $10 \mathrm{mr}$ & $10 \mathrm{~s}$ & $5 \mathrm{mr}$ & 4 & 10 & 2 & 5.3 \\
\hline 366 & ETW17-50 & KU18BWPL1_10 & 0 & $10 \mathrm{~s}$ & $\operatorname{tmr}$ & 0 & 10 & 0.4 & 3.5 \\
\hline 371 & ETW17-88 & KU18BWPL1_29 & 0 & 0 & $5 \mathrm{mr}$ & 0 & 0 & 2 & 0.7 \\
\hline
\end{tabular}

$\mathrm{CI}=$ coefficient of infection, $\mathrm{ACI}=$ average coefficient of infection

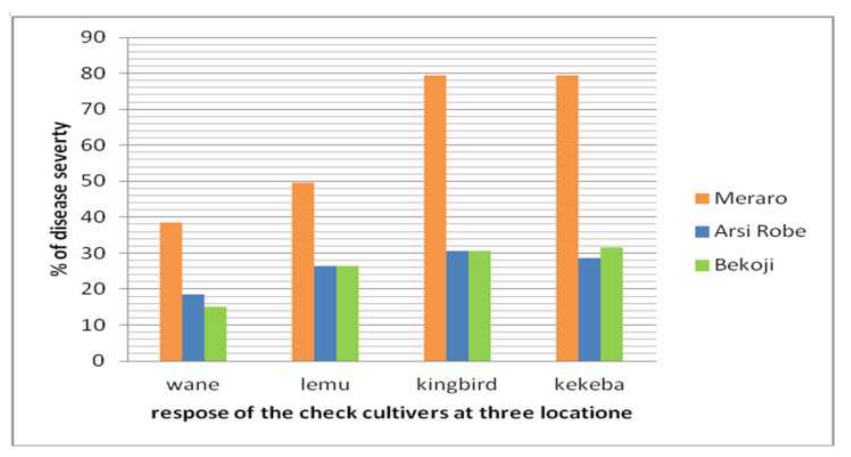

Figure 3. Disease severty of the check cultivers and it is respons of the yellow rust at Meraro, Arsi Robe and Bekoji in 2019.

\section{Discussion}

According to Admassu et al. [2] reported that indigenous germplasm evaluations against yellow rust in field condition indicated that most of the lines were moderately resistant after the resistance status which is suggested to use in the wheat breeding program because resistant varieties are the best option for successful wheat production. The field data indicated that the variability of yellow rust in severity and infection response of genotype/elite lines, and check cultivars at all testing site, Meraro, Bekoji and Arsi-robe respectively (Tables 2 and 3), indicated that the yellow rust pathogen populations have differences in their virulence profiles. More genotype/lines were found to be more susceptible at Meraro and Bekoji than Arsi-robe. The results clearly indicate the broad range of yellow rust in reaction from resistance to susceptible for yellow rust in breeder's germplasm. Therefore, it is concluded that some of the wheat germplasm had a great potential to be used against yellow rust. this result similar with Ayele, 2002 Some of the advanced bread wheat lines and commercial cultivars, which showed susceptible reaction at seedling stage exhibited low terminal yellow rust severities under field conditions in Ethiopia (Ayele, 2002). Finally, this study indicated that most of the bread wheat genotype/lines contained different resistance range when compared to the commercial cultivars. Therefore, identifying resistant bread wheat genotype/lines have been vital as sources of resistance to the prevailing races of yellow rust in Ethiopia.

\section{Conclusion}

The genotype/lines that confirm low level of yellow rust severities from $R$ to MR reactions to yellow rust in all test locations, can be utilized as resistant parental lines in the wheat breeding programmed or they can be advanced to yield trials for the development of high yielding and yellow rust resistant cultivars to fight for new evolving races of yellow rust.

\section{References}

[1] Abebe T, Woldeab G, Dawit W (2012). Analysis of pathogen virulence of wheat yellow rust and cultivar reaction to virulent races in Tigray, Ethiopia. Afr. J. Plan. Sci. 6: 244-50.

[2] Admassu, B., Friedt, W., Ordon, F., 2012. Yellow rust seedling resistance genes in Ethiopian wheat cultivars and breeding lines. African Crop Science Journal 20, 149-162. 
[3] Afzal S, Haque M, Ahmedani M, Bashir S, Rattu A (2007). Assessment of yield losses caused by puccinia striformis triggering stripe rust in the most common wheat varieties. Pak. J. Bot. 39: 2127-2134.

[4] Ayele Badebo and Wondimu Bayu. 1992. The importance of stripe rust in the major wheat producing regions of Ethiopia during 1988-1990. In: Tanner DG., and W. Mwangi (eds.). Proceedings of the seventh regional wheat workshop for Eastern, Central and Southern Africa. Nakuru, Kenya: CIMMYT. 196-202. pp.

[5] Chen XM (2005). Epidemiology and control of stripe rust (puccinia striiformis f.Sp. Tritici) on wheat. Can. J. Plant Pathol. 27: 314-337.

[6] CSA (2017). Report on area and production of major crops (For private peasant holding, Meher Season Volume 1). Addis Ababa, Ethiopia: Central Statistical Agency.

[7] Dereje Hailu. 2003. Effects of yellow rust (Puccinia striiformis) on yield, yield components and quality of improved bread wheat (Triticum aestivum L.) varieties. MSc. Thesis. Alemaya University, Alemaya, Ethiopia. 105 p.

[8] Eshetu Bekele, 1985. Review of research on diseases of barley, tef and wheat in Ethiopia. Pp. 79-108. In: Tsedeke
Abate (ed). A review of crop protection research in Ethiopia. Proceedings of the first crop protection symposium. IAR, Addis Ababa, Ethiopia.

[9] Hawkesford MJ, Araus J, Park R, Derini DC, Miralles D, Shen T, Zhang J, Parry MAJ (2013). Prospects of doubling global wheat yields. Food and En. Sec. 2: 34-48.

[10] Haile JK, Hammer K, Badebo A, Singh RP, Roder MS (2012). Haplotype analysis of molecular markers linked to yellow rust resistance genes in Ethiopian improved durum wheat varieties and tetraploid wheat landraces. Genet. Resour. Crop Evol. 60: 853-864.

[11] Khanna R, Bansal U, Saini R (2005). Genetics of adult plant stripe rust resistance in csp44, a selection from australian wheat. J Genet. 84: 337-340.

[12] Mozgovoy AF (1987) Stripe rust of wheat: Problems, situation in Ethiopia and practical recommendations W heat Rust Disease Workshop, Ambo, Ethiopia. pp. 39-77.

[13] Peterson RF, Campbell AB, Hannah AE (1948) A diagrammatic scale for estimating rust intensity on leaves and stems of cereals. Can J Res 26: 496-500.

[14] Stubbs RW, Prescott JM, Sarrri EE, Dubin HJ (1986). Cereal Disease Methodology Manual. CIMMYT, El Batan, Mexico. 